\section{Transplante de Pâncreas Isolado (órgão total) com Drenagem Vesical. Relato do Primeivo Caso do Brasil}

\section{apresentação de caso}

\section{RESUMO}

O transplante de pâncreas representa, no momento, a única terapêutica capaz de determinar estado normoglicêmico constante em pacientes com diabetes mellitus do tipo 1 (DM1), sendo indicado particularmente nas formas graves da doença, geralmente traduzidas pelas complicações secundárias como a retinopatia, neuropatia $e$ nefropatia. Sua indicação mais consagrada é em associação ao transplante renal para portadores de DMl com insuficiência renal, correspondendo a cerca de $85 \%$ dos transplantes de pâncreas no mundo. $O$ transplante de pâncreas após rim constitui outra indicação aceita, uma vez que o paciente submetido previamente ao transplante renal já se encontra sob o uso da imunossupressão. O transplante de pâncreas isolado permanece tema controverso, mas pode ser empregado em pacientes com DM instável ou com complicações secundárias da doença e função renal preservada. No presente artigo, relata-se 0 primeiro caso de transplante de pâncreas isolado empregando-se órgão total com drenagem vesical realizado no Brasil para o tratamento do DM instável. (Arq Bras Endocrinol Metab 1999;43/5: 393-398)

Unitermos: Transplante de pâncreas; Transplante renal; Diabetes mellitus; Nefropatia diabética

\begin{abstract}
Pancreas transplantation is currently the only treatment capable of establishing a constant normoglycemic state in type 1 diabetic patients (DM 1). It has been particularly indicated in the most severe forms of the disease, which usually goes along with secondary complications such as retinopathy, neuropathy and nephropathy. Pancreas transplantation has been mostly used in association to kidney transplant in end-stage renal failure DM1 patients and corresponds to $85 \%$ of all pancreas transplantation. Other indication is the pancreas after kidney, once the patient previously submitted to kidney transplant is already under immunossupression. Pancreas transplant alone remains a controversial issue, however it may be indicated in brittle DM or in those with other secondary complications and stable kidney function. This paper reports the first case of pancreas transplant alone (whole organ with bladder drainage) performed in Brazil for treatment of brittle DM. (Arq Bras Endocrinol Metab 1999;43/5: 393-398)
\end{abstract}

Keywords: Pancreas transplantation; Kidney transplantation; Diabetes mellitus; Diabetic nephropathy

O TRANSPLANTE DE PÂNCREAS (TP) constitui atualmente o único recurso terapéutico capaz de manter estado normoglicêmico permanente nos portadores de diabetes mellitus do tipo l (DMl) (1-3).

O número de TP vem crescendo progressivamente, atingindo cerca de 1.000 casos anuais ao redor do mundo e totalizando mais de 10.000 procedimentos já realizados até o momento (4).
Marcelo Perosa Tércio Genzini Antônio O. Gil Paulo J.G. Goldstein Fernando Pandullo Guido Fornasari Luiz A. Menegazzo Irene Noronha

Serviço de Hepatologia e Transplantes de Órgãos, Hospital São Camilo, São Paulo, SP 
Sua indicação mais consagrada é em associação ao transplante renal para portadores de DMl e nefropatia sob tratamento dialítico ou na iminência desta terapêutica. Cerca de $85 \%$ dos TP realizados no mundo enquadram-se nesta modalidade (4), denominados transplante de pâncreas e rim simultâneo (TPRS). Outras duas indicações também descritas são: a) Transplante de Pâncreas após Rim (TPAR), em portadores de DMl já submetidos ao transplante renal e, portanto, já sob o uso de imunossupressão; b) Transplante de Pâncreas Isolado (TPI) em duas situlaçōes: $\mathbf{l}^{\mathrm{a}}$ ) portadores de DMI em sua forma instável, caracterizada por pacientes incapacitados, ou cujo estilo de vida seja interrompido por mais de 3 vezes por semana devido a episódios repetidos de hipo ou hiperglicemia, desde que adequadamente educados e habituados às técnicas de terapia intensiva com insulina (5); $2^{\mathrm{a}}$ ) pacientes com duas ou mais complicações secundárias da doença (6).

No Brasil, o número de TP ainda é pequeno, limitando-se a alguns relatos de TPI com pâncreas segmentar nas décadas de 60 e $70(7,8)$ e experiência inicial com TPRS no Rio Grande do Sul (9) e de nosso próprio grupo (6).

Relata-se, no presente artigo, o primeiro caso de TPI em nosso meio, utilizando-se o órgão total e drenagem vesical para tratamento do "brittle diabetes".

\section{RELATO DE CASO}

Paciente do sexo feminino, 27 anos, branca, portadora de DM1 há 13 anos, em uso de insulina exógena na dose de 18 unidades/dia. Apesar de controle domiciliar rigoroso e acompanhamento contínuo com endocrinologista, usando diferentes esquemas de insulinoterapia, a paciente evoluiu com DM instável, principalmente nos últimos seis meses, necessitando de uma a duas internaçōes mensais por crises de hipo ou hiperglicemia, além de retinopatia e nefropatia incipientes e neuropatia autonômica grave. Devido a esta última complicação, apresentava diarréia crônica, com 10 a 20 episódios de evacuações diárias, motivo também de várias internações, o que a levou a estado de desnutrição grave. Pesquisou-se eventual doença de má absorção intestinal que justificasse o quadro, afastando-se qualquer afeç̧ão desta ordem. A paciente foi submetida a extensa avaliação multidisciplinar pré-transplante que incluiu investigaçăo cardiovascular, respiratória, digestiva, nefrológica, urológica, oftalmológica, neurológica, endócrina, psicológica e nutricional. Na tabela 1 , expressam-se os principais exames laboratoriais pré-operatórios:

Para conclusão da investigação renal, procedeuse à biópsia de rim a céu aberto, que demonstrou glomeruloesclerose diabética e nefropatia por IgA.

Diante desta evolução grave, com piora progressiva do estado geral e da qualidade de vida, optou-se pelo TPI como último recurso para o controle da doença.

Realizou-se o TPI em 08/09/97, que transcorreu sem intercorrências. $O$ doador foi paciente do sexo masculino, 33 anos de idade, vítima de trauma crânioencefálico há dois dias, sem antecedentes de DM, perfil bioquímico normal e que se encontrava estável hemodinamicamente, usando dopamina em dose baixa. Utilizou-se do mesmo doador o figado, rins e córneas. Para preservação do pâncreas, empregou-se um litro de solução da Universidade de Wisconsin infundida pela aorta "in situ”. Optou-se pela utilização do pâncreas - órgão total - com segmento de duodeno e drenagem vesical de secreção exócrina (Figura 1).O acesso para a cirurgia do receptor deu-se através de incisão de Gibson à direita, realizando-se anastomose venosa e arterial nos vasos ilíacos externos do receptor de forma término-lateral com suturas contínuas de polipropilene 5.0 e 6.0 , respectivamente.

Tabela 1. Perfil Laboratorial Pré-Transplante.

- Glicemia de jejum: 230mg/dL

- Uréia: 88 mg/dL

- Depuração de creatinina : $66.76 \mathrm{~mL} / \mathrm{min}$

- Sódio: $137 \mathrm{meq} / \mathrm{L}$

- Cálcio lônico: $1.16 \mathrm{mmol} / \mathrm{L}$

- Amilase: $93 \mathrm{U} / \mathrm{L}$

- Proteínas totais: $6,3 \mathrm{~g} / \mathrm{dL}$

- Hemoglobina: $6,8 \mathrm{~g} / \mathrm{dL}$

- Leucócitos: 9800

- Tempo de Protrombina: $100 \%$ (INR: 1,0)

- Tempo de Tromboplastina Parcial

Ativada: $21,1 \mathrm{~s}$ ( R: 0,84)

- Gasometria:- pH: 7,339

- pCO2: $34,3 \mathrm{mmHg}$

- BE: - 6,6

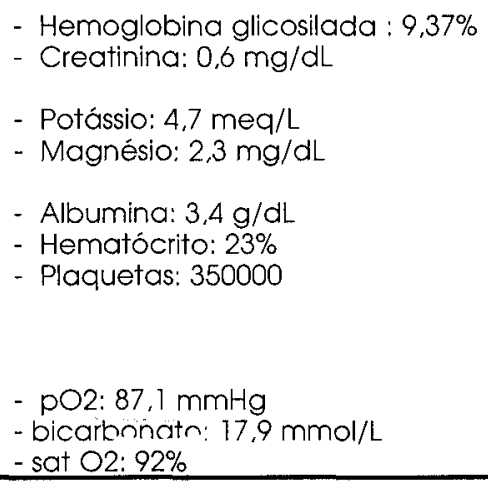




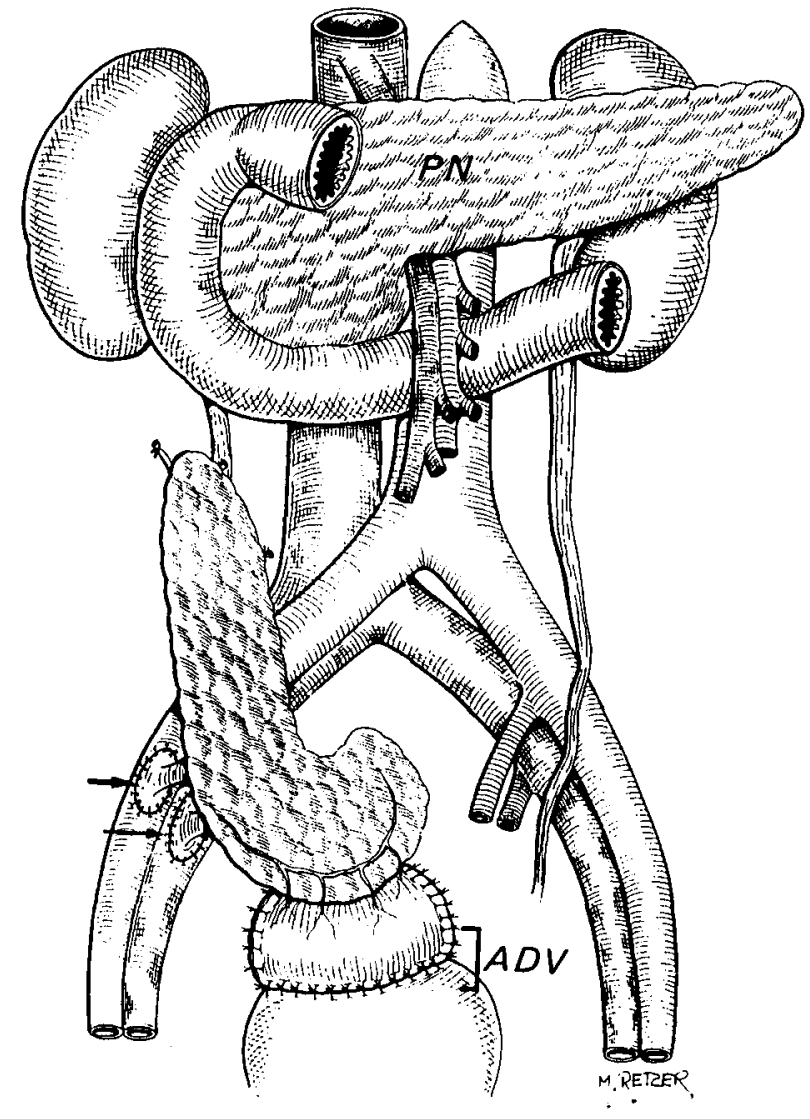

Figura 1. Transplante de Pâncreas Isolado: Aspecto Final Enxerto pancreático posicionado na fossa ilíaca direita, intraperitonealmente, destacando-se: a) Posição do pâncreas nativo (PN); b) Anastomose duodeno-vesical (ADV); c) Anastomose arterial na artéria ilíaca externa do receptor (seta menor), e; d) Anastomose venosa na veia ilíaca externa do receptor (seta maior).

Após conclusão das anastomoses vasculares, abriu-se janela peritoneal ampla, posicionando-se o pâncreas dentro da cavidade abdominal. O tempo operatório e de isquemia pancreática foi, respectivamente, de $3 \mathrm{~h}$ e $8 \mathrm{~h} 45 \mathrm{~min}$, sendo administrado três unidades de concentrado de hemácias durante o procedimento, dado que o nível de hemoglobina sérica de entrada da paciente era de $6,8 \mathrm{~g} / \mathrm{dL}$.

Empregoul-se imunossupressão quádrupla seqüencial, com Orthoclone OKT3 (OKT3) $5 \mathrm{mg} / \mathrm{dia}$ nos dez primeiros dias, manutenção com Tacrolimus (FK506), Micofenolato Mofetil e corticosteróides. Como terapia antimicrobiana, utilizou-se clindamicina e ceftazidima por sete dias e fraxiparina seguido de dipiridamol para profilaxia de fenômenos trombóticos.

A paciente evoluiu euglicêmica e insulino-independente desde o pós-operatório imediato, recebendo alta da UTI após dois dias. Também apresentou rápi- da melhora da neuropatia autonômica, traduzida por ausência de episódios de diarréia algumas semanas após o transplante.

Como complicação precoce, desenvolveu hematúria, tratada com irrigação vesical por dois dias. Recebeu alta hospitalar no $26^{\circ}$ dia pós-operatório euglicêmica, insulino-independente, com nível de glicemia de jejum de $80 \mathrm{mg} / \mathrm{dl}$ e amilase urinária de $5.110 \mathrm{UI} /$ hora.

Durante o seguimento tardio, foi readmitida por três oportunidades. Com 45 dias de pós-operatório, desenvolveu celulite em flanco direito e coleção peri-pancreática, tratada com sucesso através de drenagem percutânea, octreotídeo subcutâneo e antibiótico-terapia com vancomicina. Apresentou também, nesta fase, retenção urinária de repetição, determinando níveis elevados de amilase sérica, caracterizando-se quadro de pancreatite de refluxo, tratado com cateterismo vesical intermitente.

Foi reinternada aos três meses de pós-operatório por apresentar outra coleção peripancreática e febre. Novamente tratada por drenagem percutânea e antibióticos. Durante esta internação apresentou redução acentuada da amilase urinária, indicando-se biópsia pancreática guiada por ultra-som, que evidenciou rejeição celular aguda moderada. Tratada com sete dias de globulina anti-timocítica, com resolução do quadro.

Desde o pós-operatório precoce, verificou-se quadro de nefrotoxicidade pelo FK506, demonstrado pelo ganho de peso, edema generalizado e níveis elevados de uréia e creatinina, havendo também dificuldade em manter-se níveis séricos desejados desta droga. Optou-se, no quarto mês pós-operatório, em conversão para ciclosporina neoral, visando níveis séricos de $300 \mathrm{ng} / \mathrm{ml}$ (método TDX), observando-se, com isto, melhora da função renal.

Ao quinto mềs pós-operatório, foi readmitida por infecção urinária, isolando-se Escherichia coli e tratada com antimicrobiano. Durante este tratamento, verificoul-se novamente redução acentuada da amilase urinária, repetindo-se a biópsia pancreática percutânea, que evidenciou desta vez rejeição celular aguda grave. Optou-se por tratamento com OKT3 por 14 dias, obtendo-se recuperação da função pancreática. Após o término deste tratamento, a paciente evoluiu com sinais flogísticos e empastamento de ambas as pernas, sem alteração vascular ao Doppler e a biópsia muscular revelou piomiosite tropical. Tratada então com vancomicina por 28 dias com remissão do quadro.

Após receber alta hospitalar, apresentou fratura espontânea do fêmur direito, necessitando de imobi- 
lização por 60 dias a nível domiciliar. Ao primeiro ano pós-operatório, encontrava-se em recuperação fisioterápica da fratura de fêmur, reiniciando deambulação e exercícios. Além disso, achava-se euglicêmica, insulino-independente, com dieta livre, recuperação de hábito intestinal, e com total restabelecimento nutricional, notando-se sensível melhora da qualidade de vida. Naquele momento, apresentou episódio de malsúbito em sua residência, dando entrada em prontoatendimento com parada cárdio-respiratória, que não respondeu às manobras de ressuscitação. A causa da morte súbita não ficou bem esclarecida mesmo após realização de necrópsia, que demonstrou apenas edema pulmonar e enxerto pancreático normal.

\section{DISCUSSĀO}

O TP constitui atualmente a única terapêutica conhecida capaz de controlar as variações glicêmicas momento a momento, normalizar os níveis de hemoglobina glicosilada e manter condição euglicêmica e de independência da insulina exógena em portadores de DMl (2). Obviamente, para se alcançar tal objetivo, faz-se necessário assumir os riscos peri-operatórios e da imunossupressão para o resto da vida.

Com o desenvolvimento técnico-cirúrgico dos procedimentos de retirada e preservação do pâncreas, da imunossupressão, dos métodos de imagem e tratamento antimicrobiano, o sucesso do TP é hoje similar aos transplantes de outros órgãos (10-12).

Do ponto de vista lógico, a principal indicação deste procedimento destina-se aos portadores de DMl e insuficiência renal, em diálise ou na iminência de diálise. Nestes, uma vez que já existe a indicação do transplante renal, a associação do TP acrescenta teoricamente apenas os riscos cirúrgicos adicionais, desde que a imunossupressão já se faz necessária $(12,13)$. Além disso, o sucesso do enxerto pancreático é classicamente superior após o transplante duplo de pâncreas/rim do que após o TPI ou TPAR $(4,12)$. Tal fato deve-se principalmente à possibilidade do enxerto renal funcionar como marcador da rejeiçăo pancreáti$\mathrm{ca}$, permitindo seu diagnóstico e tratamento mais precoce e portanto minimizando a perda de enxertos pancreáticos por esta complicação. Por estas razões é que $85 \%$ dos TP realizados no mundo são em associação ao transplante renal (4).

O TPAR constitui outra indicação aceita, uma vez que o paciente submetido previamente ao transplante renal já se encontra sob uso da imunossupressão (2).

O TPI por sua vez persiste como tema controverso, defendido por vários centros $(2,4,12,14)$, mas refutado por outros (15-16). A razão para tal controvérsia é o fato de estar se propondo a independência da insulina exógena às custas da necessidade da imunossupressão, sem a justificativa de um transplante renal concomitante. Além disso, não existem, até o momento, estudos prospectivos comparando sobrevivência a longo prazo e evolução das complicações secundárias do DM em diabéticos insulino-dependentes submetidos ou não ao TPI (17).

Entretanto, existe uma minoria de pacientes que, mesmo sob tratamento e seguimento clínico rigoroso, irão evoluir com DM instável, caracterizado por freqüentes crises de descompensação por cetoacidose, coma hipo ou hiperglicêmico e/ou complicações secundárias da doença. De fato, para esta categoria de pacientes, o DM assume estado de iminente risco de vida, além de promover rápida deterioração clínica e qualidade de vida bastante precária. Nestas situações, parece razoável assumirem-se os riscos cirúrgicos e da imunossupressão inerentes ao TPI $(1,12)$.

Tendo em vista que o TP é indicado apenas para casos de $\mathrm{DMl}$, torna-se imperativa adequada caracterização desta forma da doença. Para tal, seguimos protocolos de outros grupos que caracterizam portadores de DMI apenas pela história clínica naqueles com início da doença ocorre até os 21 anos de idade $(12,18)$. Cuidado especial é dirigido para se excluírem casos suspeitos de DM do tipo 2. Assim, candidatos com história familiar marcante, início tardio da doença, obesidade ao início da doença, ou início durante a gravidez são submetidos à dosagem sérica de peptídio C, que deve permanecer $<0,2 \mathrm{ng} / \mathrm{ml}$, mesmo após estímulo com níveis de glicemía acima de $300 \mathrm{mg} / \mathrm{dL}$, para serem aceitos ao transplante $(5,14)$.

Os resultados obtidos com o TPI, segundo análise mundial, ficam aquém do alcançado com o transplante duplo no que tange à sobrevida do enxerto, proporcionando apenas $50 \%$ de sucesso em um ano (4). A sobrevida do paciente é semelhante após as duas categorias de transplante de pâncreas (TPI e TPRS), em torno de $90 \%$ no primeiro ano $(4,12)$. A polêmica da indicação e seleção dos pacientes aliada a resultados mais limitados oferecidos pelo TPI fazem com que sua realização e aceitação sejam mais contidas. Todavia, novos esquemas de imunossupressão e postura mais liberal em realizar biópsias do enxerto pancreático têm incrementado muito os resultados dos TPI, colocando-os praticamente em igual índice de sucesso aos transplantes duplos $(12,14,18)$.

No caso em questão, a paciente reunia os critérios clínicos de gravidade que justificam o TPI. Sua família mostrava-se bastante rigorosa com os cuidados 
diários que o DM exige e estava devidamente esclarecida sobre os riscos da doença e do transplante. Apesar do seguimento criterioso com endocrinologista, com tentativas de diversos esquemas de insulinoterapia, não se conseguiu evitar o desenvolvimento das complicações secundárias. Além de cursar com a forma instável da doença, já apresentava também retinopatia e nefropatia incipiente e neuropatia autonômica importante, levando-a a grau de desnutrição grave.

Acompanhou-se esta paciente por dois anos antes de se indicar o transplante, durante o que se verificou alteração renal sempre discreta e não grave o suficiente para justificar o TPRS. Em uma fase inicial, os resultados limitados com o TPI divulgados na literatura pouco nos estimulava a dar sequiência nesta direção.

Motivados pelas publicações mais recentes, incluindo novos esquemas de imunossupressão com maior sucesso do procedimento $(12,16)$, colocou-se tal opção à paciente e familiares, que prontamente aceitaram a proposta.

Realizou-se o TPI sem complicações técnicas, uma vez que já se dispunha de experiência inicial com nove TPRS naquele momento. Procurou-se respeitar as recomendações do protocolo de Maryland $(12,16)$, associando-se FK506 e micofenolato mofetil aos corticosteróides. Infelizmente a manutenção do FK506 não foi tolerada pela paciente, sendo convertido para ciclosporina Neoral com sucesso na reversão da nefrotoxicidade. Além disso, fomos igualmente liberais na realização da biópsia pancreática do enxerto, recorrendo a tal método diagnóstico por duas vezes e, em ambas, confirmando-se o diagnóstico de rejeição com ilhotas pancreáticas preservadas e, portanto, ainda passível de tratamento.

Acreditamos que o grande número de complicações apresentado pela paciente deva-se principalmente ao seu estado geral bastante comprometido no pré-operatório. Entretanto, mesmo diante destas complicações, observou-se sensível melhora do estado geral e da qualidade de vida. Infelizmente fomos surpreendidos por este episódio de morte súbita em um momento que a paciente encontrava-se em sua melhor condição metabólica e nutricional.

Concluiu-se neste primeiro caso de TPI que o procedimento é perfeitamente factível do ponto de vista técnico, mas que o laborioso manuseio e as complicações pós-operatórias exigem em primeiro lugar adequada indicação, onde o risco do DM seja maior do que o risco do TPI, e, em segundo, experiência prévia da equipe com o procedimento que, a nosso ver, deva ser adquirida inicialmente com os TPRS.

\section{REFERÊNCIAS}

1. Larsen JL, Stratta RJ. Pancreas transplantation: a treatment option for insulin-dependent diabetes mellitus. Diabetes Metab 1996;22:139-46.

2. Stratta RJ, Taylor RJ, Gill IS. Pancreas transplantation: a Managed Cure Approach to Diabetes. Curr Probl Surg 1996;33:711-806

3. Sutherland DER, Coming of age for pancreas transplantation. West J Med 1989;150:314-8.

4. Gruessner A, Sutherland DER. Pancreas transplantation in the United States and Non/US as report to the United Network for Organ Sharing (UNOS) and the International Pancreas Transplant Registry (IPTR). In: Cecka JM, Terasaki PI, editors. Clinical Transplants 1996. Los Angeles: UCLA Tissue Typing Laboratory, 1997:47-68.

5. Fajans SS. Classification and Diagnosis of Diabetes. In: Porte JrD. Sherwin RS, editors. Diabetes Mellitus. Stanford: Appleton \& Lange, 1996:357-72.

6. Miranda MP. Estado atual e experiência clínica inicial com o transplante de pâncreas. Dissertação apresentada à Faculdade de Medicina da Universidade de São Paulo para a obtenção do Título de Mestre em Medicina. 1997.

7. Pinotti HW, Raia AA, Ellenbogen $G$, Wajchemberg BL. Transplante humano de pâncreas. In: Alualização Cirúrgica. São Paulo: Johnson\&Johnson 1971:338-41.

8. Teixeira ED, Faria R, Monteiro $G$, Bandeira R, Cenzo M, Calicchio T, et al. Resultado imediato do primeiro transplante de pâncreas isolado do mundo. Hospital $1969 ; 75: 147-51$

9. Miranda V, Keite E, Bittar AE, Garcia C, Blanchini JJ, Goldani GP, et al. Combined kidney and pancreas transplantation: a Latin American Center Experience. Transplant Proc 1995:2:1827.

10. Shaffer D. Lewis WD, Jenkins RL, Monaco AP. Combined liver and whole pancreas procurement in donors with a replaced right hepatic artery. Surg Gynecol Obstet 1992; 175:204-7.

11. Sollinger HW, Ploeg RJ, Eckhoff DE. Two hundred consecutive simultaneous pancreas-kidney transplants with bladder drainage. Surgery 1993; 1 14:736-44.

12. Gruessner RWG, Sutherland DER, Najarian JS, Dunn DL, Gruessner AC. Solitary pancreas transplantation for nonuremic patients with labile insulin-dependent diabetes mellitus. Transplantation 1997;64:1572-7.

13. Stratta RJ, Taylor RJ, Ozakj CF, Bynon JS, Miller SA, Baker $\mathrm{TL}$, et al. The analysis of benefit and risk of combined pancreatic and renal transplantation versus renal transplantation alone. Surg Gynecol Obstet 1993;177:163-71.

14. Bartlett ST, Scheitzer EJ, Johnson LB, Kuo PC, Papadimitriou JC. Drachemberg CB, et al. Equivalent success of simultaneous pancreas kidney and solitary pancreas transplantation. Ann Surg 1996:224:440-52.

15. Nerup J. Is there a need for pancreas transplantation? Transplant Proc 1993;25:52-4.

16. Remuzi $G$, Ruggenenti P. Mauer SM. Pancreas and kidney/pancreas transplants: experimental medicine or real improvement? Lancet 1994;343:27-31. 
17. Sutherland DER. Pancreas transplantation: indications and outcomes. Acta Diabetol 1992;28: 185-8.

18. Bartlett ST, Kuo PC, Johnson LB, Lim JW, Schweitzer EJ. Pancreas transplantation at the University of Maryland. In: Cecka JM. Terasaki PI, editors. Clinical Transplants 1996. Los Angeles: UCLA Tissue Typing Laboratory, 1997:271-80.
Endereço para correspondência:

Marcelo Perosa

Rua Maestro Cardim 377 - cj. 75

01323-001 São Paulo, SP

Fax: 2831450 